\title{
THE EFFECT OF Nano-MgO ON THE MECHANICAL AND FLAMMABILITY PROPERTIES OF HYBRID NANO COMPOSITES FROM WOOD FLOUR-POLYETHYLENE
}

\author{
Majid Kiaei ${ }^{1, \$}$, Yaser Rastegar Moghdam ${ }^{2}$, Behzad Kord $^{3}$, Ahmad Samariha $^{4}$
}

\begin{abstract}
This study considered the effect of nanomagnesium oxide on the mechanical and flammability features of composites made of wood flour and high-density polyethylene. A sample of wood flour was made from the mixture of hardwoods and high density polyethylene with the weight ratio of $50 \%$. Maleic anhydride was added as a compatibilizer ( $2 \mathrm{phc}$ ), and nanomagnesium oxide was applied at 6 levels $(0,1,2,3,4,5 \mathrm{phc})$. These materials were mixed, and samples were prepared with determined sizes by injection molding machine. The samples were subjected to flexural tests to examine the mechanical features, and to study flammability strength, various tests were conducted with a cone calorimeter, including the amount of char residue, total smoke production, time to ignition, and heat release rate, according to ASTM E1354-92 (1992). The addition of up to 3 phe nanomagnesium oxide increased flexural strength and modulus, but further additions decreased these values. The addition of $5 \mathrm{phc}$ nanomagnesium oxide increased the char residue and ignition time, and it decreased the heat release rate, total smoke production, and burning rate. Scanning electron microscopy and energy dispersive X-ray (EDX) analysis indicated the improper transmittance of nanomagnesium oxide and accumulations in the samples.
\end{abstract}

Keywords: Char residue, flexural modulus, high density polyethylene, nanomagnesium oxide, total smoke production.

\section{INTRODUCTION}

One of the main problems of wood plastic composites is their high rate of flammability. Different measurements have been taken about the safety of using fire retardants. Some polymers, such as polyvinyl chloride, are inflammable because of the presence of a halogen element, while some others, such as polypropylene, polyethylene, polystyrene, and polyester, etc., are completely flammable and need late burners. Using late burners, such as organic halogenated compounds, antimony oxide, aluminum and magnesium hydroxide, organic phosphate and boron compounds, has become widespread in making composites. However, large amounts of these compounds should be used to be effective in late burning. While these additions increase density and decrease flexibility and mechanical features, various problems occur during the production of composites. Furthermore, these compounds cause environmental problems because they create poisonous gas, smoke, and carbon monoxide. Using new chemical compounds with different dimensions in nanoscales has been required because they can improve the features of polymer products (Kiaei et al. 2014).

\footnotetext{
${ }^{1}$ Department of Wood and Paper Engineering, Chalous Branch, Islamic Azad University, Chalous, Iran.

${ }^{2}$ Department of Wood and Paper Engineering, Chalous Branch, Islamic Azad University, Chalous, Iran.

${ }^{3}$ Department of Paper and Packaging Technology, Faculty of Chemistry and Petrochemical Engineering, Standard

Research Institute (SRI), Karaj, Iran.

${ }^{4}$ Young Researchers and Elites Club, Science and Research Branch, Islamic Azad University, Tehran, Iran.

•Corresponding author: mjd_kia59@yahoo.com

Received: 01.12.2016 Accepted: 09.07.2017
} 
Polymer materials usually are reinforced by fillers to modify mechanical features. Recently, polymer composites that are reinforced by nanophase have drawn attention in research and industry. Nano composites form new types of polymer composites in which nanoparticles are used (Poletto 2016). One of the most widely used nanoparticles in the medical and industrial fields is nanomagnesium oxide. These materials are used mostly as fungicides and antibiotics. They are also used to produce electronic devices, catalysts, ceramics, oil, color, etc. An 8,7\% demand enhancement of these materials is predicted from 2013 to 2018 (Mazaheri et al. 2014).

Sahraeian (2004) compared the flammability of 3 polymer groups (thermoplastic, thermoset, and elastomer) with their nanocomposites containing $5 \%$ modified clay. The results indicated the reduction of flammability for all nanocomposites of polymer-clay, so that the effect of nanoclay particles was significant on reduction of flammability and improvement of thermoplastic thermal sustainability.

A research on the effect of nanoclay particles on flammability features of composites made of wood fibers and high-density polyethylene indicated that enhancement of nanoclay particles reduced ignition time to $18 \%$ (Guo et al. 2007).

Kord (2012) studied the effect of nanoclay particles on physical and flammability features of high density polyethylene-wood flour composites and claimed that enhancement of nanoclay particles reduced water absorption, thickness swelling, burning amount, released heat amount, and total produced smoke of wood plastic composites. However, the amounts of char residue and ignition time of nanocomposites have been increased by enhancement of nanoclay particles.

Nemati et al. (2016) studied the effect of nanoclay on the flammability and morphological features of nano composites made of recycled polystyrene, wood flour and reported that enhancement of nanoclay particles reduced sample flammability.

Samariha et al. (2015) in a study entitled "effect of nanoclay contents on properties of bagasse flour/ high density polyethylene/nanoclay composites" reported that the tensile and flexural modulus increased with an increase in nanoclay content. Increasing the nanoclay content at $2 \mathrm{wt} \%$, the tensile and flexural strengths of the composite were increased.

Although there has been considerable research conducted to examine the effect of nanoparticles on the characteristics of wood plastic composites, there are no enough information regarding the influence of nonmetals oxides on the performance of natural fiber plastic composites is available. The present article is a comprehensive investigation on the effect of nanomagnesium oxide on the mechanical, flammability, and morphological properties of composites based on wood flour/polyethylene.

\section{MATERIAL AND METHODS}

\section{Materials}

Mixed hardwood flour was passed through a sieve of 80 meshes, and the rest was passed through the sieve of 100 meshes as filler. High-density polyethylene (HDPE; H500, Bandar Imam Petrochemical Company, Mahshar, Iran) with melting flow index of $23 \mathrm{~g} / 10 \mathrm{~min}$ and density of $0,965 \mathrm{gr} / \mathrm{cm}^{3}$ was used as the polymer matrix. To create compatibility between wood flour and polyethylene, 2 phc maleic anhydride joint with polyethylene (MAPE; KJS 111, Kimia Javid Sepahan Company, Isfahan, Iran) with a melt flow index of $35 \mathrm{~g} / 10 \mathrm{~min}$ was used. Moreover, nanomagnesium oxide (Sigma-Aldrich, St. Louis, MO, USA) was used at 6 levels of $0,1,2,3,4$, and 5 phc. Nano magnesium oxide particles had a white color and $98 \%$ purity, and their size was $20 \mathrm{~nm}$. 


\section{Methods}

\section{Mixing materials}

Polymer matrix (high density polyethylene), wood flour, compatibilizer (MAPE), and nanomagnesium oxide were mixed together according to Table 1 . The polymer matrix with wood flour, adapter, and nanomagnesium oxide were mixed in a Collin antithetic round extruder (GmbH Company, Ebersberg, Germany). The heat regions of the extruder were $165,170,175$, and $180^{\circ} \mathrm{C}$ for regions 1 through 4 . The rotational spiral speed was adjusted to $60 \mathrm{r} / \mathrm{min}$; melt mixed materials were transformed to a granule-by-granule machine model WG-LS200/200 made by the Wieser Company, Hamburg, Germany.

Table 1. Compositions of the studied formulations.

\begin{tabular}{|c|c|c|c|c|}
\hline Sample code & $\begin{array}{l}\text { Wood flour content } \\
(w t \%)\end{array}$ & $\begin{array}{l}\text { HDPE content } \\
(w t \%)\end{array}$ & $\begin{array}{c}\text { MAPE } \\
\left(\mathbf{p h c} \mathbf{c}^{*}\right)\end{array}$ & $\begin{array}{l}\text { Nano-MgO content } \\
\text { (phc) }\end{array}$ \\
\hline 50W50H2M & 50 & 50 & 2 & 0 \\
\hline $50 \mathrm{~W} 50 \mathrm{H} 2 \mathrm{M} 1 \mathrm{~N}$ & 50 & 50 & 2 & 1 \\
\hline $50 \mathrm{~W} 50 \mathrm{H} 2 \mathrm{M} 2 \mathrm{~N}$ & 50 & 50 & 2 & 2 \\
\hline $50 \mathrm{~W} 50 \mathrm{H} 2 \mathrm{M} 3 \mathrm{~N}$ & 50 & 50 & 2 & 3 \\
\hline $50 \mathrm{~W} 50 \mathrm{H} 2 \mathrm{M} 4 \mathrm{~N}$ & 50 & 50 & 2 & 4 \\
\hline $50 \mathrm{~W} 50 \mathrm{H} 2 \mathrm{M} 5 \mathrm{~N}$ & 50 & 50 & 2 & 5 \\
\hline
\end{tabular}

\section{Sample production}

To prepare samples, first granules of each compound were dried for $24 \mathrm{~h}$ at $85{ }^{\circ} \mathrm{C}$, and then they were made in semi industrial injection molding machine model MPC-40 (Aslanian Machine, Tehran, Iran) under $190{ }^{\circ} \mathrm{C}$ for the stretching and bending tests. The specimens were stored under controlled conditions $\left(65 \pm 5 \%\right.$ relative humidity and $\left.20 \pm 2{ }^{\circ} \mathrm{C}\right)$ for at least $40 \mathrm{~h}$ prior to bending tests according to ASTM D-790-10 (2010).

A laboratory press (Toyoseiki, Tokyo, Japan) was used to create samples for flammability tests. The samples were prepared at $200{ }^{\circ} \mathrm{C}$ and $25 \mathrm{MPa}$ pressure for $4 \mathrm{~min}$. The boards were cooled at $80^{\circ} \mathrm{C}$ with continued pressure.

\section{Mechanical properties}

The standard of ASTM D790-10 (2010) was applied to test the flexural modulus and strength at a speed of $2 \mathrm{~mm} / \mathrm{min}$ using an Instron Universal Testing Machine (model 1186, Instron Crop, Canton, Mass, USA). The specimen dimensions were $105 \mathrm{~mm} \times 13 \mathrm{~mm} \times 5 \mathrm{~mm}$ (length $\times$ width $\times$ thickness) for the flexural tests.

\section{Determination of flammability}

The samples with dimensions of $100 \mathrm{~mm} \times 100 \mathrm{~mm} \times 6 \mathrm{~mm}$ were prepared as sheets. The combustion parameters, such as char residue (CR), total smoke production (TSP), time to ignition (TTI), and heat release rate (HRR) tests were measured according to the ASTM E1354-92 (1992) with a cone calorimeter (FTT Company, East Grinstead, UK). The tests were conducted at an incident heat flux of $50 \mathrm{~kW} / \mathrm{m}^{2}$. The burning rate (BR) test was carried out by a horizontal burning test device (Jiangning Courty, Nanjing, China), according to standard ASTM D635-98 (1998). For each flammability treatment level, one replicates were measured for each property were reported.

\section{Scanning electron microscopy (SEM)}

A model VEGA-II scanning electron microscope (TESCAN Company, Czech Republic) was used. 
The energy dispersive spectroscopy (EDX) technique was used to determine nanomagnesium oxide, and its distribution status was considered in the wood plastic composite samples, from flexural strength specimens used for SEM.

\section{Statistical analysis}

To determine the effect of nanomagnesium oxide on the mechanical properties, statistical analysis was conducted using the SPSS (IBM Software, Armonk, New York, version 20) programming method in conjunction with the analysis of variance (ANOVA) techniques. The average values of mechanical properties were compared and classified by Duncan test at the $95 \%$ confidence level.

\section{RESULTS AND DISCUSSION}

\section{Mechanical Properties}

In this study, nanomagnesium oxide was used at six levels $(0,1,2,3,4$, and 5 phc); the $F$ values and the significance level are indicated in Table 2. The analysis of variance (ANOVA) indicated that the nanomagnesium oxide level had significant effects on flexural strength and flexural modulus at the $95 \%$ level.

Table 2. Statistical analysis of variance (ANOVA) for effect of Nano-MgO on the mechanical properties of WF/HDPE composites.

\begin{tabular}{|c|c|c|}
\hline Sample code & Flexural Strength $(\mathrm{MPa})$ & Flexural Modulus (MPa) \\
\hline $50 \mathrm{~W} 50 \mathrm{H} 2 \mathrm{M}$ & $26,07^{\circ}(1,95)$ & $1975,0^{c}(250,14)$ \\
\hline $50 \mathrm{~W} 50 \mathrm{H} 2 \mathrm{M} 1 \mathrm{~N}$ & $32,93^{\mathrm{b}}(1,65)$ & $2075,0^{\mathrm{bc}}(32,91)$ \\
\hline $50 \mathrm{~W} 50 \mathrm{H} 2 \mathrm{M} 2 \mathrm{~N}$ & $35,53^{\mathrm{b}}(3,83)$ & $2170,33^{\text {bc }}(166,50)$ \\
\hline $50 \mathrm{~W} 50 \mathrm{H} 2 \mathrm{M} 3 \mathrm{~N}$ & $46,27^{\mathrm{a}}(5,74)$ & $2561,67^{\mathrm{a}}(233,58)$ \\
\hline $50 \mathrm{~W} 50 \mathrm{H} 2 \mathrm{M} 4 \mathrm{~N}$ & $37,10^{\mathrm{b}}(2,08)$ & $2286,67^{\mathrm{ab}}(39,88)$ \\
\hline 50W50H2M5N & $38,93^{\mathrm{b}}(2,41)$ & $2481,67^{\mathrm{a}}(78,82)$ \\
\hline F-Value & $12,478^{*}$ & $6,193^{*}$ \\
\hline \multicolumn{3}{|c|}{$\begin{array}{l}{ }^{*} 95 \% \text { significance level; ns no significance } \\
\text { the Duncan ranking of the averages at a } 95 \% \text { confidence interval.) } \\
\text { Values in parentheses are standard deviation }\end{array}$} \\
\hline
\end{tabular}

\section{Flexural strength and modulus}

In the flexural test, one side of the sample was stretched, and the other side was pressed. Therefore, the two factors of distribution and wetting affected this feature (Gao et al. 2008). Trend variations of flexural strength and flexural modulus at different levels of nanomagnesium oxide are shown in Table 2. The highest and lowest means of flexural strength were attributed to the sample of 3 phc $(46,27$ $\mathrm{MPa})$ and $0 \mathrm{phc}(26,07 \mathrm{MPa})$. The highest and lowest means of flexural modulus were attributed to the sample of $3 \mathrm{phc}(2561 \mathrm{MPa})$ and $0 \mathrm{phc}(1975 \mathrm{MPa})$.

Enhancement of flexural strength and modulus was attributed to better distribution and homogeneous fibers in polymer matrix that could lead to the enhancement of interaction between lignocellulose materials and polymer matrix, and, eventually, enhancement of allowable stress; this confirmed the findings of other researchers (Balasuriya et al. 2001, Gao et al. 2012).

Enhancement of nanomagnesium oxide first increased flexural strength and modulus to 3 phc, and then they decreased; enhancement of nanoparticles in nanocomposites reflected the interfacial effect of organic chains and nanoparticles. Moreover, non-homogeneity and high ratio of surface to volume in nanomagnesium oxide and organic materials affected the boosting capability of nanoparticles (Wu et al. 2007). However, adding nanomaterials can increase composite strength (Asif et al. 2007). Therefore, 
the results showed that enhancement of nanomagnesium oxide increased flexural strength and modulus of wood plastic composites, as noted by Deka and Maji (2012).

\section{Flammability Features}

Changes of the level of composite char residue at different levels of nano magnesium oxide are shown in Figure 1. The highest and lowest means of char residue were attributed to the sample of 5 phc $(51,67 \%)$ and $0 \%(18,43 \%)$.

Changes of the level of composites ignition time is indicated in Figure 2 at different levels of nanomagnesium oxide. The highest and lowest means of ignition time were attributed to the sample of 5 phc $(79,12 \mathrm{~s})$ and 0 phc $(29,33 \mathrm{~s})$.

Changes of the level of composites total smoke production was indicated in Figure 3 at different levels of nanomagnesium oxide. The highest and lowest means of total smoke production were attributed to the sample of 0 phc $\left(320,83 \mathrm{~m}^{2} / \mathrm{kg}\right)$ and $5 \mathrm{phc}\left(223,92 \mathrm{~m}^{2} / \mathrm{kg}\right)$.

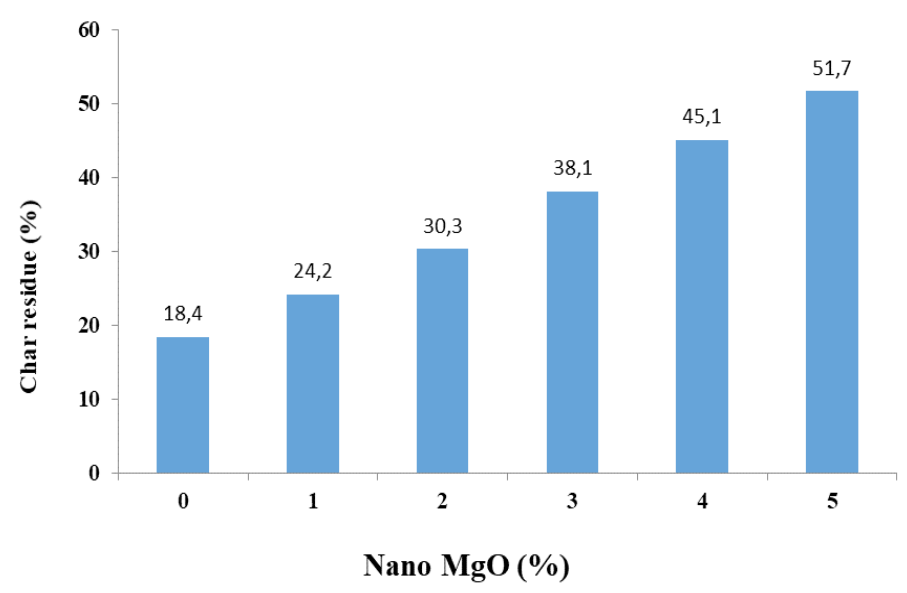

Figure 1. The effect of nano magnesium oxide on char residue amount.

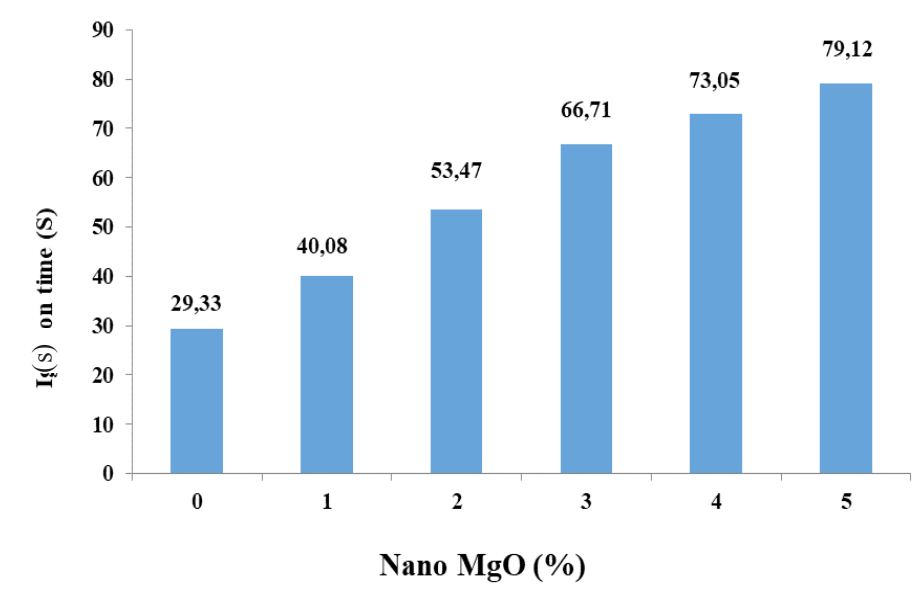

Figure 2. The effect of nanomagnesium oxide on ignition time. 


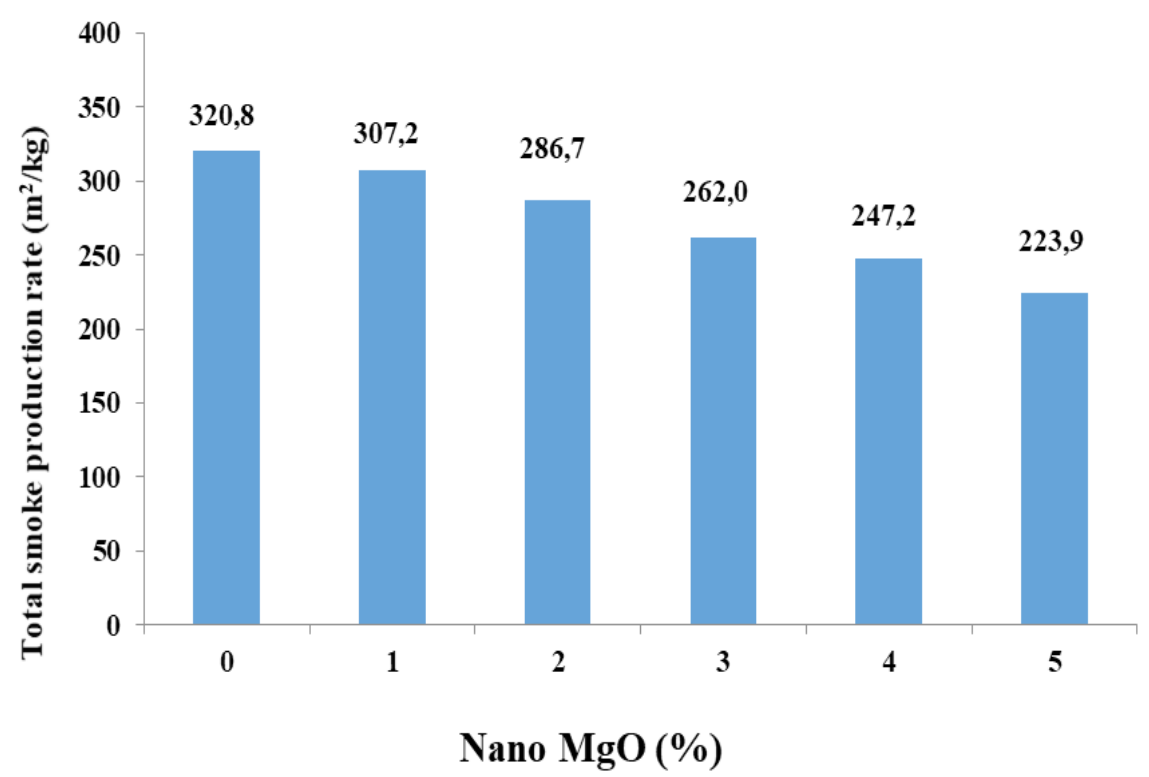

Figure 3. The effect of nanomagnesium oxide on total produced smoke.

Changes of the level of composites burning rate is indicated in Figure 4 at different levels of nanomagnesium oxide. The highest and lowest means of burning rate were attributed to the sample of $0 \mathrm{phc}(43,16 \mathrm{~mm} / \mathrm{min})$ and $5 \mathrm{phc}(23,14 \mathrm{~mm} / \mathrm{min})$.

Changes of the level of composites heat release rate is indicated in Figure 5 at different levels of nanomagnesium oxide. The highest and lowest means of heat release rate were attributed to the sample of $0 \mathrm{phc}\left(83,62 \mathrm{~kW} / \mathrm{m}^{2}\right)$ and $5 \mathrm{phc}\left(44,95 \mathrm{~kW} / \mathrm{m}^{2}\right)$.

As observed in Figure 1, Figure 2, Figure 3, Figure 4 and Figure 5, enhancement of nanomagnesium oxide from 0 to $5 \mathrm{phc}$ in nanocomposites, the amount of char residue and ignition time increased; while heat release amount, total smoke produced, and burning rate decreased. When a composite containing nanomagnesium oxide was burnt, a char layer was made by nanomagnesium oxide particles on external layer of composites and this insulated lower layer and postponed burning. In addition, nanomagnesium oxide had high coefficient that could increase heat analysis temperature and heat sustainability of composites. Enhancement of thermal sustainability in nanocomposites postponed penetration of oxygen in to polymer matrix. However, improvement of thermal sustainability was attributed to the ability of nanoparticles in crystallization and increasing temperature required for ignition. Oxygen emission and volatile compounds emersion were postponed by agglomeration of nanoparticles and then ignition time of composites was postponed. In addition, adding nanomagnesium oxide to wood plastic composites reduces oxygen penetration significantly (Deka and Maji 2012). These findings were similar to those of Sahraeian (2004), Guo et al. (2007), and Kord (2012). 


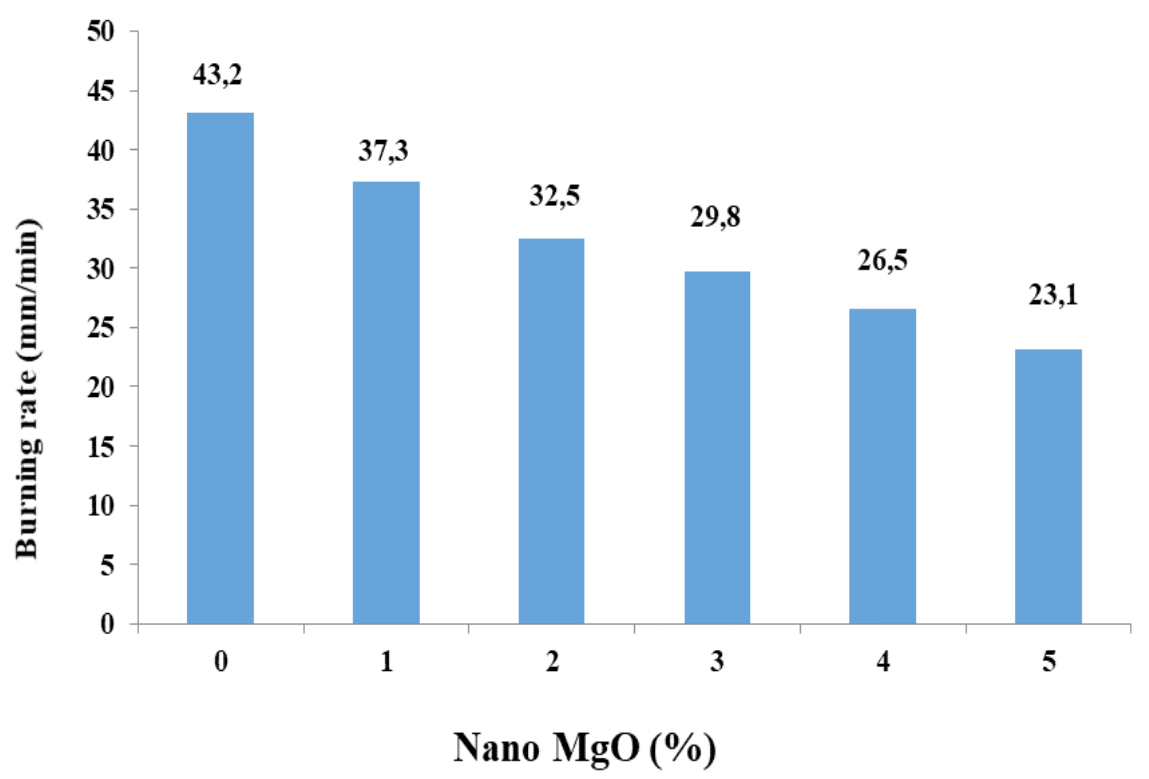

Figure 4. The effect of nanomagnesium oxide on burning rate.

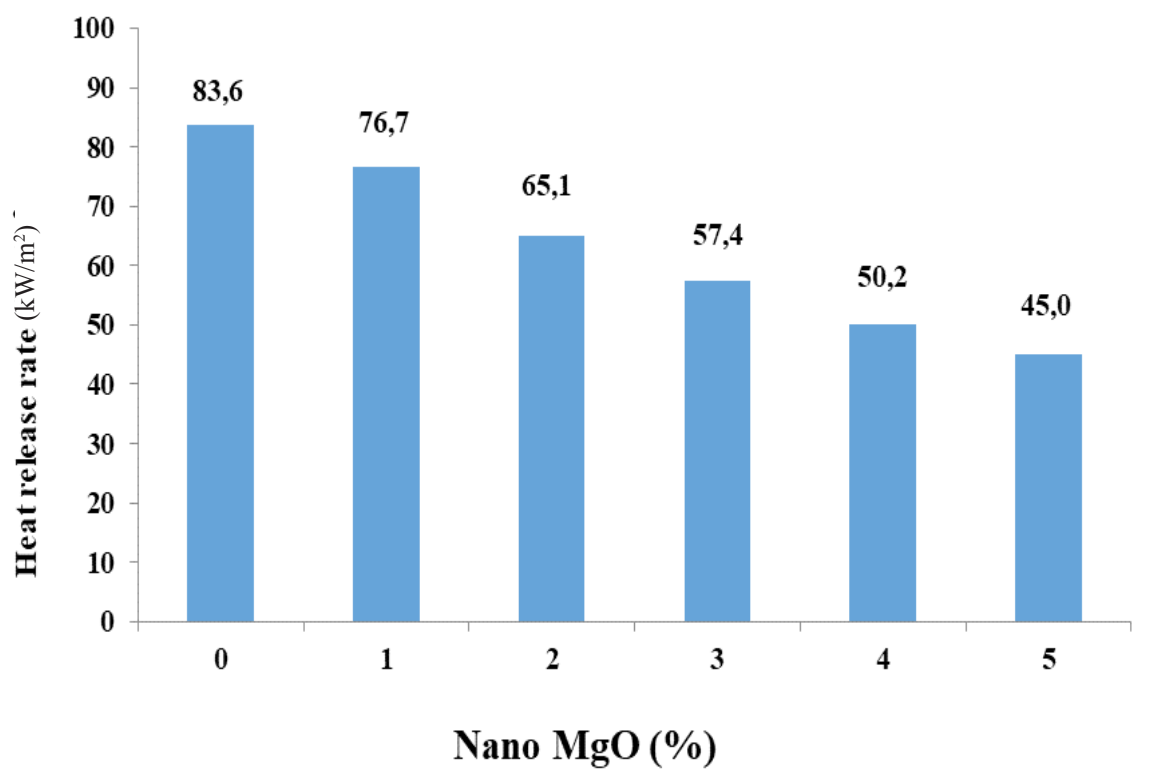

Figure 5. The effect of nanomagnesium oxide on released heat.

\section{Morphological Features}

SEM micrographs show the fracture surfaces of the composites at different loadings of Nano$\mathrm{MgO}$ in Figure 6. As can be seen, in the composites at lower Nano-MgO content the well-dispersed nanoparticles results to better stress or strain distribution in the composite (Figure 6a and Figure 6b). This dispersion state demonstrated that the interfacial adhesion between Nano-MgO, wood flour, and polymer matrix was markedly improved and further contributed to the stress transfer from fiber to Nano-MgO, and consequently enhanced the mechanical performance of the composites. As illustrated 
in Figure 6c, with increasing the Nano-MgO content from 3 to 5 phc, some reign of agglomerated nanoparticles can be seen.

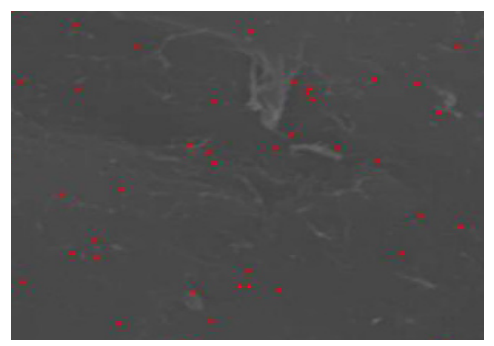

(a)

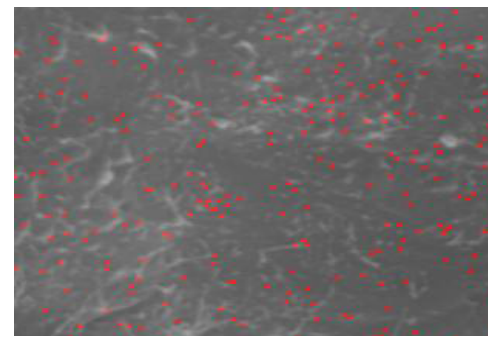

(b)

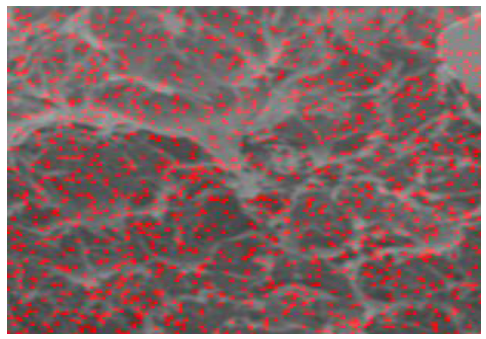

(c)

Figure 6. SEM of composites with (a) $1 \%$, (b) $3 \%$, and (c) $5 \%$ nanomagnesium oxide.

\section{CONCLUSIONS}

This study considered the effect of nanomagnesium oxide on the mechanical and flammability features of high-density hardwood/polyethylene composites.

Flexural strength and modulus of composites obtained from 5\% nanomagnesium oxide were 49,4 and $25,7 \%$, respectively, more than samples without nanomagnesium oxide.

The addition of 5 phe nanomagnesium oxide increased char residue amount and ignition time to 180,4 and $169,8 \%$, respectively.

The enhancement of nanomagnesium oxide to 5 phc decreased the released heat, total produced smoke, and burning rate to 86,$51 ; 43,27$ and $86,02 \%$, respectively.

SEM and EDX pictures taken from samples including nanomagnesium oxide ( 1 to 5 phc) showed improper distribution and accumulation of nanomagnesium oxide, which weakened the mechanical features of nanocomposites. 


\section{REFERENCES}

Asif, A. L.; Roa, V.; Ninan, K. N. 2007. Hydroxyl terminated poly (ether ketone) with pendant methyl group-toughened epoxy ternary nanocomposites: Preparation, morphology and thermomechanical properties. Journal of Applied Polymer Science 106(5): 3793-3799.

American Society for Testing and Materials. ASTM. 2010. Standard test method for bending properties of unreinforced and reinforced plastics and electrical insulating materials, D790-10. West Conshohocken, PA, USA.

American Society for Testing and Materials. ASTM. 1998. Standard test method for rate of burning and/or extent and time of burning of plastics in a horizontal position, D635-98. West Conshohocken, PA.

American Society for Testing and Materials. ASTM. 1992. Standard test method for heat and visible smoke release rates for materials and products using an oxygen consumption calorimeter, E1354-92, West Conshohocken, PA.

Balasuriya, P.W.; Ye, L.; Mai, Y.W. 2001. Mechanical properties of wood flake-polyethylene composites. Part 1: Effects of processing methods and matrix melt flow behavior. Composites: Part A 32(5): 619-629.

Kiaei, M.; Kord, B.; Vaysi, R. 2014. Influence of residual lignin content on physical and mechanical properties of kraft pulp/pp composites. Maderas-Cienc Tecnol 16(4): 495-503.

Deka, B.K.; Maji, T.K. 2012. Effect of nanoclay and $\mathrm{ZnO}$ on the physical and chemical properties of wood polymer nanocomposite. Journal of Applied Polymer Science 124(4): 2919-2929.

Gao, H.; Song, Y.M.; Wang, Q.W.; Han, Z.; Zhang, M.L. 2008. Rheological and mechanical properties of wood fiber-PP/PE blend composites. Journal of Forestry Research 19(4): 315-318.

Gao, H.; Xie, Y.; Ou, R.; Wang, Q. 2012. Grafting effects of polypropylene/polyethylene blends with maleic anhydride on the properties of the resulting wood-plastic composites. Composites Part A: Applied Science and Manufacturing 43(1): 150-157.

Guo, G.; Park, C.B.; Lee, Y.H.; Kim, Y.S.; and Sain, M. 2007. Flame retarding effect of nanoclay on wood-fiber composites. Polymer Engineering and Science 47(3): 330-336.

Kord, B. 2012. Effect of nanoclay particles on the physical properties and flammability of HDPE/ wood flour composites. Journal of Wood and Forest Science and Technology 18(4): 131-143.

Mazaheri, N.; Karimi, A.; Salavati, H.; Rezaei Zarchi, S.; Khalilian, S.; Rezaei Ranjbar Sardari, R. 2014. Investigating the effect of intraperitoneal injection of magnesium oxide nanoparticles on the liver and kidney function of rat in vivo. Journal of Shahid Sadoughi University of Medical Science 22(4): 1430-1438.

Nemati, M.; Eslam, H.K.; Talaeipour, M.; Bazyar, B.; Samariha, A. 2016. Effect of nanoclay on flammability behavior and morphology of nanocomposites from wood flour and polystyrene materials. BioResources 11(1): 748-758.

Poletto, M. 2016. Effect of styrene maleic anhydride on physical and mechanical properties of recycled polystyrene wood flour composites. Maderas-Cienc Tecnol 18(4): 533-542.

Sahraeian, R. 2004. Flammability Behavior of Nanocomposites of Polymer-Clay Soil, Master's Thesis, Tarbiat Modarres University, Tehran, Iran. 
Samariha, A.; Hemmasi, A.H.; Ghasemi, I.; Bazyar, B.; Nemati, M. 2015. Effect of nanoclay contents on properties, of bagasse flour/reprocessed high density polyethylene/nanoclay composites. Maderas-Cienc Tecnol 17(3): 637-646.

Wu, Q.; Lei, Y.; Yao, F.; Xu, Y.; Lian, K. 2007. Properties of HDPE/clay/wood nanocomposites. in: 2007 First International Conference on Integration and Commercialization of Micro and Nanosystems, Sanya, China, pp. 181-188. 